\title{
Cost-Effectiveness of Maxillary Implant-Supported Overdentures Compared to Complete Dentures and Implant-Supported Fixed Dental Prostheses-A
} Systematic Review

\author{
Peyman Ghiasi ${ }^{1, *}$, Camilla Ahlgren ${ }^{2}$, Liselott Arnebrant ${ }^{3}$, Sofia Tranæus ${ }^{4}$ and Christel Larsson ${ }^{5}$ \\ ${ }^{1}$ PhD-student, Department of Prosthodontics, Faculty of Odontology, Malmö University, Malmö, Sweden \\ ${ }^{2}$ Senior Consultant, Specialized Clinic of Prosthodontics, Folktandvården Skåne (Public Dental Service Skåne), Lund, Sweden \\ ${ }^{3}$ Professor Emerita, Department of Prosthodontics, Faculty of Odontology, Malmö University, Malmö, Sweden \\ ${ }^{4}$ Adjunct Professor, Health Technology Assessment-Odontology (HTA-O), Faculty of Odontology, Malmö University, Malmö, Sweden \\ ${ }^{5}$ Associate Professor, Department of Prosthodontics, Faculty of Odontology, Malmö University, Malmö, Sweden
}

*Corresponding author: Peyman Ghiasi, PhD-student, Department of Prosthodontics, Faculty of Odontology, Malmö University, 20506 Malmö, Sweden, E-mail: peyman.ghiasi@mau.se

Received: 24 Feb, 2021 | Accepted: 18 Mar, 2021 | Published: 25 Mar, 2021

Citation: Ghiasi P, Ahlgren C, Arnebrant L, Tranæus S, Larsson C (2021) Cost-Effectiveness of Maxillary Implant-Supported Overdentures Compared to Complete Dentures and Implant-Supported Fixed Dental Prostheses-A Systematic Review. Int J Dent Oral Health 7(3): dx.doi.org/10.16966/23787090.357

Copyright: (C2021 Ghiasi P, et al. This is an open-access article distributed under the terms of the Creative Commons Attribution License, which permits unrestricted use, distribution, and reproduction in any medium, provided the original author and source are credited.

\begin{abstract}
Purpose: Implant-supported restorations are well-documented treatments from a clinical perspective. Analysis of their cost-effectiveness is however limited, especially for implant-supported overdentures. The objective of this systematic review was to assess the literature on cost-effectiveness regarding maxillary implant-supported overdentures compared to complete dentures and fixed implant-supported restorations.
\end{abstract}

Methods: Three electronic databases: PubMed, Cochrane Library and Web of Science, were searched for original studies including economic analysis of implant-supported overdenture treatment in the maxilla.

Results: The literature search resulted in 190 articles. After elimination of duplicates and assessment of eligibility according to pre-established criteria, two studies presenting the results from a single patient cohort were included and read in full text.

Discussion: Cost-effectiveness analysis is important for society as well as the individual patient. This is true for any treatment, but perhaps particularly for extensive treatments such as treatment of edentulism.

Conclusion: The level of evidence for the cost-effectiveness of maxillary implant-supported overdentures is very low due to a severe lack of studies. Further research is needed to provide guidance in the clinical decision on the best choice of treatment.

Keywords: Dental implants; Overdenture; Maxilla; Cost-effectiveness

\section{Introduction}

Edentulism entails significant negative effects for the individual in terms of reduced functions such as speech and chewing, lip and cheek support and aesthetics. Edentulism may be treated using either removable or fixed restorations. The choice of treatment is related to the patient's general health, oral status, expectations and economy. Complete dentures may function well but many patients desire improved fixation of the prosthesis. Implant-supported fixed dental prostheses are well-documented evidence-based treatments, also resulting in high patient satisfaction [1-3]. In situations where fixed dental prostheses are not suitable or possible, an implantretained overdenture, often requiring fewer implants as support, may be adequate. It has been described that satisfaction and chewing ability were higher among patients treated with implant- retained mandibular overdentures, than in a group treated with complete dentures [4]. Furthermore, implant-retained mandibular overdentures can improve bite force and reduce the duration of the chewing cycle [5].

There is sound evidence on the clinical outcome, as well as the patient-reported outcome, on implant-retained mandibular overdentures which in some cases are preferred over implantsupported fixed prostheses [6,7]. Capability to speak, aesthetics, easy cleaning, and general satisfaction were shown to be the factors with the highest influence on the choice between an implant-supported fixed prosthesis and an implant-supported overdenture, in favor of the overdenture [7]. Especially elderly patients have been prone to choose removable prostheses as they have found them significantly easier to clean [8]. 
In comparison to implant-supported mandibular overdentures, there is less scientific evidence for implant-supported maxillary overdentures with regard to design, retention, biological and technical parameters, as well as patient-reported outcomes [9]. However, studies have shown that maxillary overdentures retained by two implants increase the oral health-related quality of life, over conventional dentures [10]. Implant-supported maxillary overdentures vary in design, from complete palatal coverage with two to four implants as support, to "horse-shoe" shaped design supported by four to six implants or more. In addition, the type of retentive system used varies considerably from single attachments to bars connecting two or several implants in a milled bar fixed-removable hybrid design [11-13].

A prosthodontic treatment carries an economic cost that includes initial cost, such as cost of labour and materials, as well as costs for maintenance and/or repair. Cost-effectiveness analysis is characterized by analysis of both costs and outcomes [14]. A cost-minimization analysis, which is a type of cost-effectiveness analysis, is applicable when two or more treatment methods achieve the same outcomes and the aim is to identify the least expensive method [14]. The intervention that incurs the lowest cost is then the one that would be most rational to implement if the goal is to minimize cost $[14,15]$. The economic cost of any treatment is perhaps particularly important for the ageing population when income streams may be decreasing or limited. It is in this group that we find the highest prevalence of edentulous patients. Costs vary for different treatment alternatives, fixed or removable, for edentulous patients [16]. The costs are likely further influenced by the particular design of the restoration which may vary considerably, e.g. in maxillary implant-supported overdentures as described above.

The dental profession needs data on both costs and outcomes for different treatment methods in order to establish a sound basis for treatment decisions $[14,15]$. The present systematic review aimed to assess evidence regarding the cost-effectiveness of implant-supported overdentures in the edentulous maxilla compared to complete dentures and fixed implant-supported restorations.

\section{Materials and Methods}

This systematic review was conducted following PRISMA (Preferred Reporting for Systematic Reviews and Meta-Analyses) guidelines. The following question was addressed:

Is treatment with overdentures on implants in the edentulous maxilla a cost-effective treatment compared to fixed implantsupported restorations or conventional removable dentures?

\section{Search strategy}

The literature search was initially conducted in July 2018 with an update conducted in December 2020. Three databases were searched: PubMed, the Cochrane Library and Web of Science. No limits were set apart from the language which was restricted to papers published in English. In addition, reference lists of selected papers were searched for non-indexed publications. For a detailed description of the search terms and strategy used, see supplementary tables S1-S3.

- Inclusion criteria were set according to the PICO approach.

- Participants: Patients treated for edentulism in the maxilla.

- Interventions: Treatment with implant-supported overdentures in the maxilla.

- Control: Treatment with fixed implant-supported restorations or removable complete dentures in the maxilla (with the same treatment target).
Supplementary Table 1: Search strategy in PubMed (U.S. National Library of Medicine), Dec10 2020.

\begin{tabular}{|c|c|c|}
\hline \multicolumn{2}{|r|}{ Edentulism } & Result \\
\hline 1 & $\begin{array}{l}\text { “Mouth, Edentulous"[Mesh] OR edentulism[Title/ } \\
\text { Abstract] OR edentulousness[Title/Abstract] OR } \\
\text { edentulous[Title/Abstract] }\end{array}$ & 18,140 \\
\hline \multicolumn{3}{|c|}{ Maxilla } \\
\hline 2 & $\begin{array}{l}\text { “Maxilla”[Mesh] OR “Palate"[Mesh] OR maxill*[Title/ } \\
\text { Abstract] OR Palat*[Title/Abstract] OR upper } \\
\text { jaw[Title/Abstract] }\end{array}$ & 156,648 \\
\hline \multicolumn{3}{|c|}{ Overlay denture } \\
\hline 3 & $\begin{array}{l}\text { "Dentures"[Mesh] OR “Dental Prosthesis"[Mesh] OR } \\
\text { dentur*[Title/Abstract] OR dental prosthes*[Title/ } \\
\text { Abstract] OR overdentur*[Title/Abstract] }\end{array}$ & 114,386 \\
\hline \multicolumn{3}{|c|}{ Cost-effectiveness } \\
\hline 4 & $\begin{array}{l}\text { (Economics[Title/Abstract]) OR cost benefit } \\
\text { analys*[Title/Abstract] OR cost*[Title/Abstract] OR } \\
\text { cost effective*[Title/Abstract] OR ((economic[Title/ } \\
\text { Abstract]) AND evaluation*[Title/Abstract]) OR } \\
\text { ((economic[Title/Abstract] AND analy*[Title/ } \\
\text { Abstract])) OR ((cost[Title/Abstract] AND analy*[Title/ } \\
\text { Abstract])) OR ((cost[Title/Abstract] AND } \\
\text { effectiveness[Title/Abstract])) OR ((cost[Title/Abstract] } \\
\text { AND benefit*[Title/Abstract])) OR ((cost[Title/ } \\
\text { Abstract] AND utilit*[Title/Abstract])) OR “Health Care } \\
\text { Costs"[Mesh] OR “Cost-Benefit Analysis"[Mesh] OR } \\
\text { ("Costs and Cost Analysis"[Mesh]) }\end{array}$ & 825,918 \\
\hline 5 & 1 AND 2 AND 3 AND 4 & 141 \\
\hline
\end{tabular}

Supplementary Table 2: Search strategy for Web of science by Thomson Reuters Dec $10^{\text {th }} 2020$.

\begin{tabular}{|c|c|c|}
\hline \multicolumn{2}{|r|}{ Edentulism } & Result \\
\hline 1 & $\begin{array}{l}\text { TS=(edentulism OR completely edentulous OR } \\
\text { edentulousness OR edentulous) }\end{array}$ & 10,166 \\
\hline \multicolumn{2}{|r|}{ Maxilla } & \\
\hline 2 & TS=(maxill* OR Palat* OR upper jaw OR upper) & 862,198 \\
\hline \multicolumn{2}{|r|}{ Overlay denture } & \\
\hline 3 & $\begin{array}{l}\text { TS=(dentur* OR dental prosthes* OR complete } \\
\text { dentur* OR overdentur* OR Overlay dentur*) }\end{array}$ & 25,628 \\
\hline \multicolumn{2}{|r|}{ Cost-effectiveness } & \\
\hline 4 & $\begin{array}{l}\text { TS=((Economics OR cost benefit analys* OR cost* OR } \\
\text { cost effective* OR health care cost*) OR (economic } \\
\text { AND evaluation*) OR (economic AND analy*) OR } \\
\text { (cost* AND analy*) OR (cost* AND effectiveness) OR } \\
\text { (cost*AND benefit*) OR (cost* AND utilit*)) }\end{array}$ & $2,249,395$ \\
\hline 5 & 1 AND 2 AND 3 AND 4 & 83 \\
\hline
\end{tabular}

- Outcome measures: Primary outcome measure: Incremental cost-effectiveness ratio (ICER). Secondary outcome measure: Costs.

- Type of Studies: Clinical trials (human in vivo studies).

- Exclusion criteria were case reports, in vitro studies, and reviews.

Data extraction and quality assessment

The screening was performed by two reviewers (PG,CA) 
Supplementary Table 3: Search strategy for Cochrane Library by Wiley Online Library Dec $10^{\text {th }} 2020$.

\begin{tabular}{|c|c|c|}
\hline \multicolumn{2}{|r|}{ Edentulism } & Result \\
\hline 1 & $\begin{array}{l}\text { MeSH descriptor: [Mouth, Edentulous] explode all trees } \\
\text { OR ti,ab,kw(edentulism OR completely edentulous OR } \\
\text { edentulousness OR edentulous) Word variations have } \\
\text { been searched }\end{array}$ & 1,780 \\
\hline \multicolumn{3}{|c|}{ Maxilla } \\
\hline 2 & $\begin{array}{l}\text { MeSH descriptor: [Maxilla] explode all trees OR } \\
\text { MeSH descriptor: [Palate] explode all trees OR } \\
\text { ti,ab,kw(maxill* OR palat* OR upper jaw OR upper) } \\
\text { Word variations have been searched }\end{array}$ & 52,768 \\
\hline \multicolumn{3}{|c|}{ Overlay denture } \\
\hline 3 & $\begin{array}{l}\text { MeSH descriptor: [Dentures] explode all trees OR } \\
\text { MeSH descriptor: [Dental Prosthesis] explode all trees } \\
\text { OR ti,ab,kw(dental prosthes* OR complete dentur* OR } \\
\text { overdentur* OR overlay dentur*) Word variations have } \\
\text { been searched }\end{array}$ & 5,341 \\
\hline \multicolumn{3}{|c|}{ Cost-effectiveness } \\
\hline 4 & $\begin{array}{l}\text { MeSH descriptor: [Costs and Cost Analysis] explode } \\
\text { all trees OR ti,ab,kw((cost benefit analys* OR cost* } \\
\text { OR cost effective*) OR (economic AND evaluation) OR } \\
\text { (economic AND analy*) OR (cost AND effectiveness) } \\
\text { OR (cost AND benefit*) OR (cost AND utilit*))Word } \\
\text { variations have been searched }\end{array}$ & 81,705 \\
\hline 5 & 1 AND 2 AND 3 AND 4 & 28 \\
\hline \multicolumn{3}{|c|}{2 Cochrane Reviews, 26 trials } \\
\hline
\end{tabular}

independently. Publications were selected based on the inclusion and exclusion criteria, through the titles and when at least one reviewer found a title interesting, the abstract was assessed. Articles that did not have an abstract available went directly to a full-text assessment. Abstracts or full texts were assessed independently by the reviewers and disagreements regarding inclusion and exclusion were resolved through discussion, based on the pre-set criteria. When necessary, a third reviewer (LA) was consulted. The risk of bias of the included studies was assessed using items for the assessment of the risk of bias, GRADE [17]. The two reviewers (PG,CA) independently undertook assessment of relevance and risk of bias, as well as data extraction from the included studies.

\section{Results}

\section{Study selection}

The literature search resulted in 141 hits in PubMed, 83 in Web of Science and 28 in Cochrane Library, in total 252 hits. Adjustment for duplicates resulted in 190 studies. The PRISMA flow diagram is depicted in figure 1. After checking for multiple entries and after assessing the relevance of the abstracts, two studies were subsequently read in full text, assessed according to the pre-established criteria and included for analysis (Table 1). A hand search of reference lists of selected papers did not yield any additional papers.

\section{Quality assessment}

The included studies were rated as having an overall high risk of bias due to issues regarding selection (no randomization, no clear inclusion and exclusion criteria), performance (non-validated questionnaire), and detection bias (unblinded).

\section{Included studies-characteristics and reported results}

The two included studies, present results from a randomized clinical trial on the same study population of 20 patients $[18,19]$. A single research group compared prosthetic treatment outcomes of fixed (10 patients) and removable implant-supported prostheses (10 patients) in the edentulous maxilla. Results were published in two separate papers. Patient satisfaction, oral health-related quality of life, and the clinician's point of view were analysed and discussed in the first publication [18]. In addition, cost-utility was accounted for. In the second publication, the clinical findings are presented and costs for maintenance are discussed [19].

In group one, ten participants were treated with a fixed detachable implant prosthesis retained by eight to ten implants. In group two, ten patients were treated with removable bar-retained, implant-supported overdenture prostheses retained by six to eight implants. In the first paper, patients' satisfaction with oral health status pre-and posttreatment was analysed together with treatment costs. The economic analysis of the treatment was estimated by each patient's bill divided by the number of units replaced and the mean value per unit was calculated for both treatment groups [18]. Chair time for the treatment and the patient's expenses such as traveling, absence from work, etc. were not included in the analyses. Costs calculated as direct costs of the treatment were summarized for each patient, including a charge for surgical and prosthetic treatment and costs of dental laboratory fees. Costs per tooth unit were estimated to compare the cost of the two treatments. The costs for fixed implant prostheses were significantly higher (average cost \$22,000) than for the removable implant-retained overdentures (average cost \$17,000), partly due to a higher number of implants. In addition, higher rates were charged for the prosthodontic procedures for fixed implant restorations. No significant differences were found between treatment groups regarding patients' satisfaction with oral health status pre-and post-treatment. All patients reported similar levels of satisfaction with their prosthetic treatment regarding comfort and retention, function, aesthetics and appearance, taste, speech, and self-esteem.

In the second paper, clinical parameters such as periodontal status, radiographic bone loss and biological and mechanical complications were recorded [19]. No significant differences were found between treatment groups. The implant survival rate was high, $97.6 \%$ for group one and $94.4 \%$, for group two after an 18-month observation period. No prostheses failed in either group during the observation period (39.2 months for group one and 27.5 months for group 2). Few complications occurred. In the fixed implant prosthesis group, one patient showed slight swelling and redness around one implant, fractures of acrylic resin veneering occurred in three cases and two cases of porcelain chipping were observed. In the overdenture group, one abutment screw fracture was observed, two attachments were replaced and two patients showed severe discoloration of denture teeth after 2 years of function. No differences in periodontal parameters were observed, however, mucosal hyperplasia was observed in two patients in group two.

All complications could be managed by chairside adjustment or repair during recall visits, hence lowering the costs instead of several appointments engaging dental technician laboratories.

\section{Discussion}

There is an inadequate scientific basis on which to determine the cost-effectiveness of maxillary implant-supported overdentures. The fact that only two publications studying maxillary overdentures were identified, evaluating one single patient cohort, critically limits 


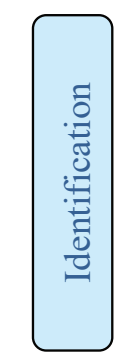

Records identified through database searching $(n=252)$

Additional records identified through hand search of reference lists $(n=0)$

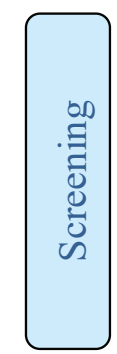

Records after duplicates removed $(\mathrm{n}=62)$
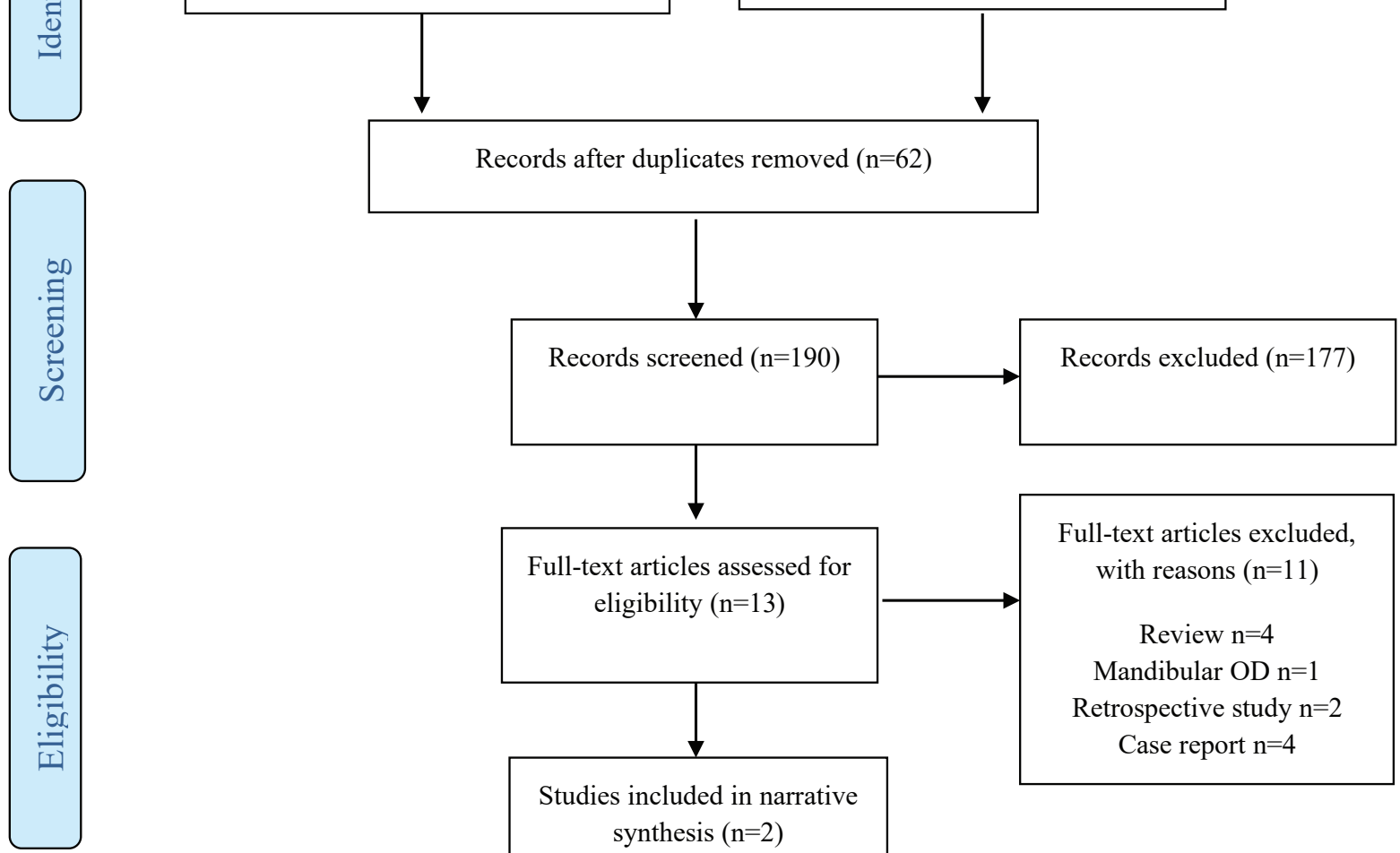

Studies included in narrative synthesis $(\mathrm{n}=2)$
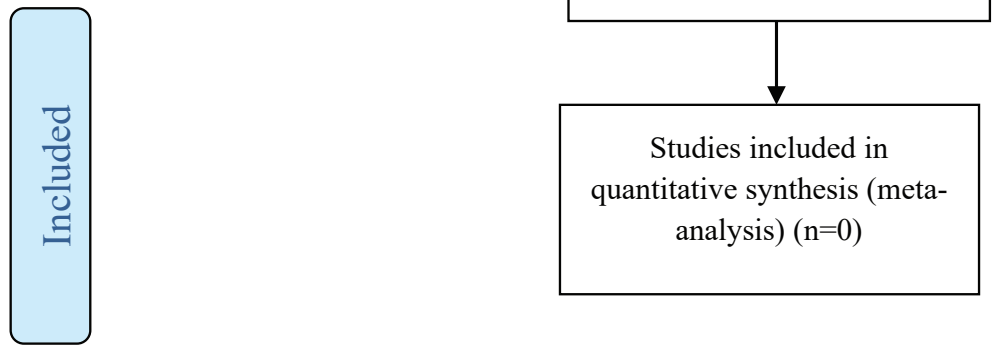

Figure 1: PRISMA flow diagram.

foundations for conclusions. The identified studies evaluated only two of three treatments, fixed restoration and overdenture, i.e., the conventional complete denture was not included for comparison. Furthermore, critical data necessary for a true cost-effectiveness analysis was not available in the included studies.

Choosing a particular treatment is a complex process involving a variety of factors. The cost of treatment is one of the more influential factors and one that is of importance for patients as well as dental professionals and society in general [20]. Health economic analyses are important for controlling limited resources in the public sector in countries with subsidized dental care [21]. To determine whether the treatment in question is cost-effective or not, the extra cost needs to be assessed in relation to the potential additional benefits. Initial costs are only one part of cost-effectiveness. The higher costs for the fixed restoration group with more implants than in the overdenture group were thus unsurprising. However, costs for maintenance and repair must also be taken into consideration [22]. Some studies have signaled an increased risk of implant failure among overdentures compared to fixed restorations [23]. Others indicate that patients with overdentures need constant maintenance follow-ups to address technical complications [24]. However, it is also well known that complications are frequently occurring among fixed implant-supported restorations [25]. The survival and complication rates of restorations are therefore an important factor to investigate as an initially costly treatment with high long-term success could be more economic than treatment with low initial cost but high need of maintenance and repair [26]. This aspect is mentioned in one of the analysed papers, but costs for repair are not calculated [19]. 
Table 1: Characteristics of articles read in full text and quality assessment of included studies.

\begin{tabular}{|c|c|c|c|c|c|c|c|c|c|c|}
\hline $\begin{array}{c}\text { Author/ } \\
\text { Year }\end{array}$ & $\begin{array}{l}\text { Study } \\
\text { design }\end{array}$ & $\begin{array}{l}\text { Patients } \\
\text { Age }\end{array}$ & $\begin{array}{c}\text { Main outcome } \\
\text { measures }\end{array}$ & Cost analysis & $\begin{array}{l}\text { Reason for } \\
\text { inclusion/ } \\
\text { exclusion }\end{array}$ & Aim & $\begin{array}{l}\text { Implants } \\
\text { Retention }\end{array}$ & Follow-up & Results & $\begin{array}{l}\text { Risk of bias } \\
\text { Comments }\end{array}$ \\
\hline $\begin{array}{l}\text { Zitzmann } \\
\text { NU, et al., } \\
{[19]^{(11)}}\end{array}$ & Prospective & $\begin{array}{l}20 \\
35-79 \\
\text { years } \\
\text { Group 1; } \\
\text { Mean age } \\
54.7 \text { years } \\
\text { Group 2; } \\
\text { Mean age } \\
60.5 \text { years }\end{array}$ & $\begin{array}{l}\text { Treatment } \\
\text { outcomes } \\
\text { of fixed or } \\
\text { removable } \\
\text { implant- } \\
\text { supported } \\
\text { prostheses in } \\
\text { the edentulous } \\
\text { maxilla: } \\
\text { clinical findings }\end{array}$ & $\begin{array}{l}\text { Direct costs } \\
\text { (incl. materials } \\
\text { and laboratory } \\
\text { fees) divided } \\
\text { by number of } \\
\text { units replaced. } \\
\text { Mean value } \\
\text { per unit } \\
\text { calculated per } \\
\text { group. }\end{array}$ & $\begin{array}{l}\text { Inclusion: } \\
\text { Clinical } \\
\text { study. Costs } \\
\text { evaluated. }\end{array}$ & $\begin{array}{l}\text { Treatment } \\
\text { outcome } \\
\text { of fixed or } \\
\text { removable } \\
\text { implant- } \\
\text { supported } \\
\text { prostheses in } \\
\text { the edentulous } \\
\text { maxilla. Part II: } \\
\text { clinical findings. }\end{array}$ & $\begin{array}{l}155 \\
\text { Brånemark } \\
\text { implants } \\
\text { (Group 1: 84, } \\
\text { Group 2: 71) } \\
6 \text { month } \\
\text { healing } \\
\text { period } \\
\text { Group 1: fixed } \\
\text { Group 2: } \\
\text { denture } \\
\text { fitted to bar } \\
\text { via Ceka } \\
\text { attachments } \\
\text { (Dolder } \\
\text { elements in } 3 \\
\text { patients) }\end{array}$ & $\begin{array}{l}39 \text { months } \\
\text { (group 1) and } \\
27 \text { months } \\
\text { (group 2), } \\
\text { after implant } \\
\text { placement. }\end{array}$ & $\begin{array}{l}\text { The study } \\
\text { demonstrated } \\
\text { high implant } \\
\text { survival rates } \\
\text { for patients } \\
\text { with either fixed } \\
\text { or removable } \\
\text { implant- } \\
\text { supported } \\
\text { prostheses in } \\
\text { the edentulous } \\
\text { maxilla. Costs } \\
\text { discussed } \\
\text { regarding } \\
\text { maintenance. }\end{array}$ & $\begin{array}{l}\text { High risk of } \\
\text { bias } \\
\text { Imprecision } \\
\text { high } \\
\text { Critical data } \\
\text { necessary } \\
\text { for an } \\
\text { economic } \\
\text { analysis } \\
\text { was not } \\
\text { available. }\end{array}$ \\
\hline $\begin{array}{l}\text { Zitzmann } \\
\text { NU, et al., } \\
{[18]^{(1)}}\end{array}$ & Prospective & \begin{tabular}{|l}
20 \\
$35-79$ \\
years \\
Group \\
$1(\mathrm{FD}) ;$ \\
Mean age \\
54.7 years \\
Group \\
$2(\mathrm{OD}) ;$ \\
Mean age \\
60.5 years
\end{tabular} & $\begin{array}{l}\text { Treatment } \\
\text { outcomes } \\
\text { of fixed or } \\
\text { removable } \\
\text { implant- } \\
\text { supported } \\
\text { prostheses in } \\
\text { the edentulous } \\
\text { maxilla: } \\
\text { patient } \\
\text { satisfaction } \\
\text { and oral health } \\
\text { related quality } \\
\text { of life }\end{array}$ & & $\begin{array}{l}\text { Inclusion: } \\
\text { Clinical study. } \\
\text { Cost-utility } \\
\text { accounted } \\
\text { for. }\end{array}$ & $\begin{array}{l}\text { Questionnaire, } \\
\text { treatment } \\
\text { outcome } \\
\text { of fixed or } \\
\text { removable } \\
\text { implant- } \\
\text { supported } \\
\text { prostheses in } \\
\text { the edentulous } \\
\text { maxilla. Part } \\
\text { I: patients' } \\
\text { assessments. }\end{array}$ & & $\begin{array}{l}\text { Questionnaire } \\
6 \text { months after } \\
\text { prosthetic } \\
\text { rehabilitation }\end{array}$ & $\begin{array}{l}\text { Rehabilitation } \\
\text { with both design } \\
\text { options led } \\
\text { to significant } \\
\text { improvements } \\
\text { in patients' } \\
\text { subjective } \\
\text { feelings. No } \\
\text { significant } \\
\text { differences were } \\
\text { found between } \\
\text { the assessments } \\
\text { of the } 2 \text { groups. } \\
\text { Economics } \\
\text { accounted for. }\end{array}$ & $\begin{array}{l}\text { High risk of } \\
\text { bias } \\
\text { Imprecision } \\
\text { high } \\
\text { Critical data } \\
\text { necessary } \\
\text { for an } \\
\text { economic } \\
\text { analysis } \\
\text { was not } \\
\text { available. }\end{array}$ \\
\hline
\end{tabular}

In addition, the cost of treatment should be compared to patient satisfaction [26]. Patient-reported outcome measures such as oralhealth-related quality of life are important to include evaluating all aspects of the treatment of patients who suffer tooth loss and its consequences [2]. This aspect was addressed in one of the identified papers [18]. Although all patients reported similar satisfaction after 6 months, additional follow-up would have been interesting to evaluate whether maintenance and repair influence patient-reported outcomes.

Previous literature suggests that dental implants can improve the retention and stability of dentures, although the initial cost of treatment is higher and increases with an increasing number of implants [27]. Thus the cost for treating an edentulous jaw with an overdenture will initially be lower due to fewer implants than a fixed implant-supported prosthesis [18]. Whether this is true in the long-term perspective is not satisfactorily investigated. A previous systematic review aimed to evaluate outcomes and cost-effectiveness of treatment methods used to rehabilitate adult patients with maxillary and/or mandibular edentulism [28]. The literature search failed to identify relevant studies to analyse the financial aspects of rehabilitation of patients with tooth loss. The findings in this systematic review also prove the lack of studies of maxillary implant-supported overdentures to scientifically support any economic advantages. This makes decision-making and treatment planning complicated for patients as well as for dentists. For a better understanding of the benefit of implant-supported treatment in the maxilla, studies should be designed to investigate all parameters in randomized controlled, prospective studies with long-term follow up, investigating both patients' and clinicians' point of view regarding the outcome as well as health economic perspectives [13]. The economic analysis should include the time spent by the dental professionals (prosthodontic and surgical) including assistants, patient-related costs including travel and loss of income when absent from work to attend treatment sessions, materials, drugs, dental laboratory work, etc., [29].

\section{Certainty of evidence}

In this systematic review, the certainty of the evidence for the costeffectiveness of treatment with implant-supported overdentures in the maxilla was rated as very low. The risk of bias in the included studies was assessed as high as patients chose treatment after the presentation of suggested costs and suitability for the individual patient. Neither patients nor dentists were blinded, which however may be difficult in clinical dental studies. The imprecision with a small sample size of patients, and the evaluation of costs and not cost-effectiveness as was the aim, is high. In addition, if the aim is to analyse cost-effectiveness, a longer follow-up would be preferred, as would a larger sample of patients. 


\section{Limitations of the study}

The main limitation of the present review is the lack of evidence. Although two publications were identified, they are based on the same patient cohort and although both papers discuss the issue of costs in relation to treatment with maxillary overdentures, none provided a true cost-effectiveness analysis. Both papers also have other limitations. This considerably limits the ability to provide guidance for clinical decisions.

The findings of the present review confirm conclusions from other papers on health economics that the quality of reporting of economic evaluations varies widely, and could benefit from improved quality assurance mechanisms $[30,31]$.

\section{Conclusion}

The level of evidence for the cost-effectiveness of maxillary implantsupported overdentures is very low due to a severe lack of studies. Further research is needed to guide the clinical decision on the best choice of treatment. Such studies should preferably be designed to investigate several parameters, including clinical and patient-related outcomes, in randomized and clinically controlled, longitudinal prospective studies with long-term follow-up.

\section{Acknowledgment}

Ms. Helena Rydberg, Martina Vall and Mr. Pär Hyberg are gratefully acknowledged for skillful support during the literature searches. Financial support from Malmö University and TePe Foundation is gratefully acknowledged.

\section{Declaration of Interests}

The authors declare no conflicts of interest.

\section{References}

1. Mericske-Stern R, Worni A (2014) Optimal number of oral implants for fixed reconstructions: A review of the literature. Eur J Oral Implantol 7: S133-S153.

2. Yao CJ, Cao C, Bornstein MM, Mattheos N (2018) Patient-reported outcome measures of edentulous patients restored with implantsupported removable and fixed prostheses: A systematic review. Clin Oral Implants Res 29: 241-254.

3. Wittneben JG, Wismeijer D, Brägger U, Joda T, Abou-Ayash S (2018) Patient-reported outcome measures focusing on aesthetics of implant- and tooth-supported fixed dental prostheses: A systematic review and meta-analysis. Clin Oral Implants Res 29: 224-240.

4. Boerrigter EM, Stegenga B, Raghoebar GM, Boering G (1995) Patient satisfaction and chewing ability with implant-retained mandibular overdentures: A comparison with new complete dentures with or without preprosthetic surgery. J Oral Maxillofac Surg 53: 1167-1173.

5. Bakke M, Holm B, Gotfredsen K (2002) Masticatory function and patient satisfaction with implant-supported mandibular overdentures: a prospective 5-year study. Int J Prosthodont 15: 575581

6. Kutkut A, Bertoli E, Frazer R, Pinto-Sinai G, Fuentealba Hidalgo R, et al. (2018) A systematic review of studies comparing conventional complete denture and implant retained overdenture. J Prosthodont Res 62: 1-9.

7. Heydecke G, Boudrias P, Awad MA, De Albuquerque RF, Lund JP, et al. (2003) Within-subject comparisons of maxillary fixed and removable implant prostheses: Patient satisfaction and choice of prosthesis. Clin Oral Implants Res 14: 125-130.
8. Feine JS, De Grandmont P, Boudrias P, Brien N, La Marche R, et al. (1994) Within-subject Comparisons of Implant-supported Mandibular Prostheses: Choice of Prosthesis. J Dent Res 73: 11051111.

9. Stoumpis C, Kohal RJ (2011) To splint or not to splint oral implants in the implant-supported overdenture therapy? A systematic literature review. J Oral Rehabil 38: 857-869.

10. Zembic A, Wismeijer D (2014) Patient-reported outcomes of maxillary implant-supported overdentures compared with conventional dentures. Clin Oral Implants Res 25: 441-450.

11. Smedberg JI, Lothigius E, Ninler K, De Buck V (1991) A new design for a hybrid prosthesis supported by osseointegrated implants: 2 . Preliminary clinical aspects. Int J Oral Maxillofac Implants 6: 154-159.

12. Ghiasi P, Ahlgren C, Larsson C, Chrcanovic BR (2021) Implant and prosthesis failure rates with implant-supported maxillary overdentures: a systematic review. Int J Prosthodont Feb 23 doi: 10.11607/ijp.6905. Online ahead of print.

13. Payne AGT, Walton TR, Walton JN, Solomons YF (2001) The Outcome of Implant Overdentures from a Prosthodontic Perspective: Proposal for a Classification Protocol. Int J Prosthodont 14: 27-32.

14. Drummond MF, Sculpher MJ, Torrance GW, O'Brien BJ, Stoddart GL (2005) Methods for the Economic Evaluation of Health Care Programmes. $3^{\text {rd }}$ Edition, Oxford University Press, Oxford, England.

15. Tickle M (1997) Clinical effectiveness and primary dental care. 2. The influence of health economics. Prim Dent Care 4: 85-87.

16. Probst LF, Vanni T, Cavalcante DFB, Silva ETD, Cavalcanti YW, et al. (2019) Cost-effectiveness of implant-supported dental prosthesis compared to conventional dental prosthesis. Rev Saude Publica 19: 1-13.

17. Guyatt GH, Oxman AD, Vist G, Kunz R, Brozek J, et al. (2011) GRADE guidelines: 4. Rating the quality of evidence-Study limitations (risk of bias). J Clin Epidemiol 64: 407-415.

18. Zitzmann NU, Marinello CP (2000) Treatment outcomes of fixed or removable implant-supported prostheses in the edentulous maxilla. Part I: Patients' assessments. J Prosthet Dent 83: 424-433.

19. Zitzmann NU, Marinello CP (2000) Treatment outcomes of fixed or removable implant-supported prostheses in the edentulous maxilla. Part II: Clinical findings. J Prosthet Dent 83: 434-442.

20. Elangovan S, Guzman-Armstrong S, Marshall TA, Johnsen DC (2018) Clinical decision making in the era of evidence-based dentistry. J Am Dent Assoc 149: 745-747.

21. SBU-Swedish Agency for Health Technology Assessment and Assessment of Social Services (2017) Assessment of Methods in Health Care: A Handbook.

22. Lewis DW (1998) Optimized therapy for the edentulous predicament: Cost-effectiveness considerations. J Prosthet Dent 79: 93-99.

23. Bergendal T, Engquist B (1998) Implant-supported overdentures: a longitudinal prospective study. Int J Oral Maxillofac Implants 13 253-262.

24. Chrcanovic BR, Ghiasi P, Kisch J, Lindh L, Larsson C (2020) Retrospective study comparing the clinical outcomes of bar-clip and ball attachment implant-supported overdentures. J Oral Sci 26: 397401.

25. Pjetursson BE, Brägger U, Lang NP, Zwahlen M (2007) Comparison of survival and complication rates of tooth-supported fixed dental prostheses (FDPs) and implant-supported FDPs and single crowns (SCs). Clin Oral Implants Res 18: 97-113. 
26. MacEntee MI, Walton JN (1998) The economics of complete dentures and implant-related services: A framework for analysis and preliminary outcomes. J Prosthet Dent 79: 24-30.

27. Zitzmann NU, Krastl G, Weiger R, Kühl S, Sendi P (2013) Costeffectiveness of anterior implants versus fixed dental prostheses. J Dent Res 92: 183-188.

28. Rohlin M, Nilner K, Davidson T, Gynther G, Hultin M, et al. (2012) Treatment of adult patients with edentulous arches: a systematic review. Int J Prosthodont 25: 553-567.
29. Marchack BW (1992) Applying business principles to a prosthodontic practice. J Prosthet Dent 67: 550-555.

30. Neumann PJ, Stone PW, Chapman RH, Sandberg EA, Bell CM (2000) The quality of reporting in published cost-utility analyses, 19761997. Ann Intern Med 132: 964-972.

31. Rosen AB, Greenberg D, Stone PW, Olchanski NV, Neumann PJ (2005) Quality of abstracts of papers reporting original cost-effectiveness analyses. Med Decis Making 25: 424-428. 